\title{
sciendo
}

\section{Modelling monthly Gross Domestic Product on the supply side. A case study for Romania}

\author{
Alina Mirela BĂLȚĂȚEANU \\ Bucharest Academy of Economic Studies, Bucharest, Romania \\ E-mail adress: alinamirelabaltateanu@gmail.com
}

\begin{abstract}
This paper aims to estimate monthly Gross Domestic Product (GDP1), which is an important aggregate indicator; It shows the trend of economic activity in the short term. Thus, the macroeconomic and financial risks in the short term with influences on financial markets and investor confidence (economic sentiment) can be identified and correlated. In addition, the monthly GDP series provides a condensed set of information (monthly data) needed to develop potential GDP estimating models correlated with inflation, unemployment and relevant indicators of labor market. Another applicability is quarterly GDP forecast at least two months ahead of the flash estimate published by National Institute of Statistics (NIS2). This article presents a method of estimating the monthly GDP on the supply side. Gross value added has been broken down into five components: industry, construction, trade and transport, other market services, other activities, the first four of which are well interpolated with unifactorial regressions and some monthly explanatory variables. The results show a high correlation between the 4 components of supply and the additional aggregated quarterly series that are also available on a monthly basis. The highest dynamics of monthly GDP was recorded in August 2017 (+9.3\%) and the lowest increase in August 2014 (+1.4\%) over the period 2014-2018. Starting in January 2018, economic growth slow down, amid a pronounced base effect of the private consumption and weakening external demand.
\end{abstract}

Keywords: monthly GDP, monthly interpolation, national accounts, modelling

\section{Introduction}

The national accounts provide a complete and coherent picture of the evolution in economy and the most relevant synthesis indicator is the gross domestic product.

The interest in recent years was high for tracking short-term phenomena, to identify possible trend changes. Statistical indicators estimated at a higher frequency allow this analysis. Thus, higher frequency data it will be available immediately within a month when phenomenon occur to produced and ensure its description with a short delay (on the other hand, GDP is released only 45 days after the close of the reference quarter).

The data provided by Eurostat include only quarterly series of national accounts and relevant monthly series on production, consumption, revenues, prices, but the latter give an incomplete description of the economy. The compilation of the monthly GDP which is the main purpose of the study, responds on the one hand to the need in providing a new monthly indicator for the entire economy, and on the other hand to fit in the current modern statistics of national accounts. The final objective would be to compile a set of monthly indicators of national accounts, in particular components of GDP on the supply side.

Monthly GDP is an important estimator of economic activity in the actual period when

\footnotetext{
${ }^{1}$ In the entire paper is mentioned acronym of the Gross Domestic Product, namely GDP.

${ }^{2}$ In the entire paper is mentioned acronym of the National Institute of Statistics, namely NIS.
} 
short-term economic factors are closely correlated with the financial ones, producing fluctuations that may affect the economy's medium-term trend. The monthly GDP is correlated with indicators such as inflation, external trade, economic sentiment, ${ }^{3}$ stock trading value, population incomes, and budget revenues, all of which being useful to guide macroeconomic policy and risk assessment, in the short term.

The study aims to highlight the correlations between the four main components of the quarterly GDP on the supply side and the corresponding series calculated by NIS that are available monthly. The last ones are important because they capture the short-term (monthly) economic phenomenon and are published earlier than the preliminary/ provisional quarterly series from the national accounts. Those monthly series, also called additional variables, are converted into quarterly series to be correlated with the GDP components. As a result of the statistical analysis, GDP is calculated on a monthly basis by summing its components, which are interpolated according to the additional monthly variables.

The statistical procedure about how GDP is calculated and estimated by NIS have several steps. Initially, the "flash" (first data) GDP is estimated by extrapolation of the seasonally adjusted quarterly series; there follows the preliminary/provisional one and two times (I and II) data estimates and after successive corrections are made within one year until the final (definitive) version of GDP is reached. Generally speaking, there is a significant correlation between the components of GDP in the provisional estimation and the various corresponding series calculated by NIS in the monthly surveys.

Subsequently, this correlation weakens because of successive revisions to GDP based on further additional information from quarterly and annual surveys.

The econometric results from the present study can give us an answer on the relevance of GDP as a monthly statistical indicator for Romania, with an acceptable correlation with the available monthly series. A high statistical relevance makes the monthly GDP to be successfully used in the quarterly forecast with at least two months before NIS estimates and at the same time is considered as an appropriate measure of economic activity on short-term (monthly).

The structure of the article is as follows: Introduction, Literature review, where the author summarizes the main approaches about monthly GDP, Methodology describes the method used with reference to GDP formation and econometric estimation, Results and discussions, analyzes the monthly data series used to estimate the monthly GDP and their statistical processing. The results obtained are presented in this section, followed in conclusions and proposals for developing the method in future research.

\footnotetext{
${ }^{3}$ The Economic Sentiment Indicator (ESI) is a composite indicator made up of five sectoral confidence indicators with different weights: Industrial confidence indicator, Services confidence indicator, Consumer confidence indicator, Construction confidence indicator Retail trade confidence indicator. Confidence indicators are arithmetic means of seasonally adjusted balances of answers to a selection of questions closely related to the reference variable they are supposed to track (e.g. industrial production for the industrial confidence indicator). Surveys are defined within the Joint Harmonised EU Programme of Business and Consumer Surveys. The economic sentiment indicator (ESI) is calculated as an index with mean value of 100 and standard deviation of 10 over a fixed standardised sample period. Data are compiled according to the Statistical classification of economic activities in the European Community, (NACE Rev. 2). Source: DG ECFIN, European Comission from www.ec.europa.eu/eurostat/web/products-datasets/-/teibs010.
} 


\section{Literature review}

Related literature highlights two types of methods used to estimate the monthly GDP, i.e. the econometric regression (simple or multiple) and the Kalman filter method.

The first statisticians who present an econometric model for estimating the monthly GDP were Chow and $\mathrm{Lin}^{4}$. In a first step, they estimated quarterly GDP regression according to some relevant aggregate quarterly variables from the available monthly data. Subsequently, the monthly series were introduced into the econometric equation to display the monthly GDP series.

Generally, the multiple regression for an unobservable monthly variable $\mathbf{y}_{\mathrm{t}}$ (monthly GDP) by the $\mathbf{x}_{\mathrm{mt}}$ explanatory series is $\boldsymbol{y}=\mathbf{X} \boldsymbol{\beta}+\mathbf{u}$, having the covariance matrix of errors $\mathbf{V}=\mathbf{E}$ $\left[\mathbf{u} \mathbf{u}^{\prime}\right]$, where the vector of the parameters $\boldsymbol{\beta}$ is estimated from the quarterly regression $\mathbf{y}^{\mathbf{I V}=}$ $\mathbf{X}^{\mathbf{I V}} \boldsymbol{\beta}+\mathbf{u}^{\mathbf{I V}}$. Chow and Lin have found the $\boldsymbol{y}$ series that best approximates the monthly GDP according to the relationship $\boldsymbol{y}=\mathbf{X} \boldsymbol{\beta} \mathbf{G L S}+\boldsymbol{\Lambda}(\mathbf{V}) \mathbf{u}^{\text {IV }}$. The series has two components: the usual one $\mathbf{X} \beta_{\text {GLS }}$ ( $\beta_{\text {GLS }}$ is the GLS estimator of the quarterly regression) and a component $\Lambda(\mathbf{V}) \mathbf{u}^{\mathbf{I V}}$ of monthly distribution of quarterly errors $\mathbf{u}^{\mathbf{I V}}$ according to the weighting matrix $\Lambda(\mathbf{V})$.

A deficiency of the method is the use of "level" series in the regression equations, these being generally non-stationary. Perfecting the method consists in using logarithm series and logarithmic differences to avoid heteroscedasticity issues. The Chow and $\operatorname{Lin}^{5}$ approach about modeling monthly GDP was improved by Astolfi and Ladiray ${ }^{6}$, Pinheiro and Coimbra ${ }^{7}$, Salazar, Smith and Weale ${ }^{8}$.

More recent studies use the Kalman filter (Bernanke, Gertler and Watson ${ }^{9}$, Cuche and Hess $^{10}$, Harvey and Pierse ${ }^{11}$ ), an iterative method that at step $k$ calculates the term $k$ of the unobservable monthly series (monthly GDP). The advantage of the method is that it can also be applied to nonlinear models. This process requires setting initial values for both the parameters and the unobservable variable and transcribing the model into a state-space form. The concept of state-space representation is to relate two equations in a single system, where the first is called the measurement equation (linking the unobservable series to the observed series and the other monthly additional variables), and the second is called the state equation (describes the dynamics of the unobservable series).

Both methods lead to similar results, while they are exactly the same (explanatory) additional variables.

\footnotetext{
${ }^{4}$ Chow G., Lin A.L., (1971), Best linear unbiased Interpolation, Distribution and Extrapolation of Time Series by Related Series, The Review of Economics and Statistics 53(4), 372-375.

${ }^{5}$ Chow G., Lin A.L., (1971), Best linear unbiased Interpolation, Distribution and Extrapolation of Time Series by Related Series, The Review of Economics and Statistics 53(4), 372-375.

${ }^{6}$ Astolfi R., Ladiray D., Mazzi G., Sartori F., Soares R., (2001), A Monthly Indicator of GDP for the Euro-zone, Office for Official Publications of the European Communities, European Commission.

7 Pinheiro M., Coimbra C., (1993), Distribution and Extrapolation of Time Series by Related Series Using Logarithms and Smoothing Penalities, Economia v.XVII, 359-374.

8 Salazar E., Smith R., Weale M., Wright S., (1994), Indicators of monthly National Accounts, Workshop on Quarterly National Accounts, Paris 5-6 December 1994.

9 Bernanke B., Gertler M., Watson M., (1997), Systemic monetary policy and the effects of oil price shocks, Brookings Papers on Economic Activity, (1):91-157.

${ }^{10}$ Cuche N., Hess M., $(1999,2000)$, Estimating monthly GDP in a general Kalman filter framework: evidence from Switzerland, Economic \& Financial Modelling, University of California at Berkeley.

${ }^{11}$ Harvey A., Pierse R., (1984), Estimating missing observations in economic time series, Journal of the American Statistical Association, 79(385):125-131.
} 
In my research, I decided to choose the first method (simple econometric regression), based on a national accounts statistical view to analyze the results.

Thus, I considered as main hypothesis the maintenance of the same type of correlation both at quarterly and monthly level between the dynamics of the series in the national accounts and the explanatory series chosen for interpolation. The correlation can be analyzed by a simple regression where the variables are growth rates or logarithmic "Year-over-Year" differences. It is better to interpolate each component of GDP separately because for this there is in the national account's statistics an "appropriate" additional series from the monthly surveys, the one used in the provisional quarterly estimates.

\section{The methodology}

According to the national accounts statistics, GDP is the final result of the production activity over a period, the quarterly level being the shortest one. The first calculation method is the production method, which is considered the most accurate when preparing preliminary estimates. Thus, GDP breaks down into:

$G D P=G V A+N T P$

where GVA = Gross Value Added to the base price;

NTP = Net Taxes on Product.

GVA is also broken down by branches of activity, each of which is evaluated separately. The main data sources used to estimate quarterly GVA by activities are the monthly statistical surveys of industrial production, construction works, services, trade, earnings, the number of employees, along with administrative sources such as the state budget and the balance of payments.

Thus, we have the following representation of gross value added:

$G V A=G I N D+G C S T+G T R T+G O M S+G P A D+G A G R$

* where the six components of the national accounts are gross value added in industry, construction, trade and transport, other market services, public administration and agriculture. Both indicators GPAD and NTP could be estimated at monthly level with the administrative information provided by the consolidated general budget, but the calculations can only be made for the current price series.

According to Romanian National Institute of Statistics, GDP is initially assessed by components in the preliminary form at constant prices in order to remove inflationary influences, most commonly expressed in average prices of the year 2000. These are also called gross series because the seasonally adjusted series obtained by the TRAMO/SEATS method (Demetra software) are calculated, too. Separately, the deflators (price indexes) are evaluated, that are required to pass to the series in nominal values.

The monthly GDP components at constant prices could be compiled using regression equations with estimated parameters based on quarterly data, where the dependent variables are the quarterly national account series mentioned above and the explanatory variables are the quarterly aggregates of monthly additional series. For example, the industrial production index and the turnover volume index in retail trade could be chosen as explanatory variables because the industry and the private consumption have important contributions to the GDP formation. 
For checking stationarity, I used the Augmented Dickey-Fuller (ADF12) test based on the assumption that the (yt) tested series follows an auto-regressive stochastic process of 1st order, AR (1), around a trend:

$$
\ln (y t)=\alpha+\beta t+\rho \ln (y(t-1))+\varepsilon t
$$

This regression is transformed into:

$$
\Delta \ln (y t)=\alpha+\beta t+\gamma \ln (y(t-1))+\varepsilon t
$$

The null hypothesis is the presence of the unit root $\rho=1$, or $\gamma=1-\rho=0$.

The procedure consists in applying the t-statistic test on the $y$ coefficient and comparing the test result with the critical values related to significance thresholds of $1 \%, 5 \%$ and $10 \%$. If the test result is less than one of the three critical values then the null hypothesis can be rejected and the analyzed series is stationary.

The quarterly series of Chow and Lin's econometric method are expressed in levels and constant prices. The method presented in this article uses all the series expressed in logarithmic differences to eliminate autocorrelation and increase the accuracy of econometric estimates. Thus, I choose for the differences $\Delta \ln (Y t)$ between times $t$ and $t-4$ in the quarterly regression, respectively for the differences $\Delta \ln (y t)$ between times $t$ and $t-12$ in the monthly estimation relation, because seasonality is present on an annual basis (Yearover-Year), both for the national accounts and for the additional monthly data.

Generally, the structural quarterly regression proposed in our analysis for a GDP component $(Y t)$, based on the quarterly aggregate of the monthly variable $(X t)$, has the following form:

$\Delta \ln Y_{t}=c_{1} \Delta \ln X_{t}+c_{2} \ln Y_{t-4}+c_{3} \ln X_{t-4}+\varepsilon_{t}$

with the corresponding monthly relationship for the best estimator of monthly national account's series $\left(y_{t}\right)$ :

$$
\Delta \ln y_{t}=c_{1} \Delta \ln x_{t}+c_{2} \ln y_{t-12}+c_{3} \ln x_{t-12}
$$

where the coefficients $\mathrm{c} 1-\mathrm{c} 3$ are estimated in the quarterly regression.

I estimated the equations by the ordinary least squares (OLS) method with robust standard error calculations taking in some cases the dummy variables.

\section{Results and discussions}

In order to achieve the desired results, that is, statistically relevant monthly series of national accounts, we have taken several steps. First, the choice was the separate estimate of the five different GDP components, which were then used to obtain the monthly series of GDP. An alternative method would have been to directly estimate the monthly GDP by using all available information. Thus, our approach should produce more reliable figures, while the second may be approximate in terms of calculation.

It needs more attention when choose monthly additional statistical series, which need to have significance and "proximity" of those quarterly series that interpolates. Some monthly series are published directly by NIS, for example the industrial production index and the construction working index. The other two, of the nature of the services, were built by

\footnotetext{
${ }^{12}$ Fuller, W. A. (1976). Introduction to Statistical Time Series. New York: John Wiley and Sons. ISBN 0-47128715-6.

Ogunc, A. \& Hill, C. (2008) Using Excel: Companion to Principles of Econometrics, Third Edition. Retrieved January 4, 2017, from:

http://econweb.tamu.edu/hwang/CLASS/Ecmt463/Lecture\%20Notes/Excel/Excel_Lessons.pdf
} 
successive aggregations from several available series. Thus, for 4 components of GDP, the most statistically relevant monthly series were found, those that are traditionally used in the procedure for estimating the provisional quarterly data.

In the present analysis, I chose for estimating the monthly GDP in constant prices of 2015 , because the additional monthly series are published by NIS as volume indices relative to the base year 2015, in which case we will use the simplified identity:

$G D P=G I N D+G C S T+G T R T+G O M S+G O T H$

where $\quad G O T H=N T P+G P A D+G A G R$

The contribution to GDP of other activities and taxes on products (GOTH) is relatively important (Table 1), with a percentage around $27 \%$ due to the dominating influence of the public administration sector (13.1\%) and taxes on the product $(9,6 \%)$, also an element of national accounts specific to the public sector.

Table 1. The contribution to the nominal value of GDP in 2018

\begin{tabular}{|l|c|c|}
\hline GDP by resources & Symbol & Percent \\
\hline Industry & GIND & 23,5 \\
\hline Construction & GCST & 5,4 \\
\hline Trade and Transport & GTRT & 18,3 \\
\hline Other market services & GOMS & 25,8 \\
\hline Other activities and taxes on products & GOTH & 27,0 \\
\hline
\end{tabular}

Source: National Institute of Statistics, Press release no.83/8 th of april 2019

\section{Data availability}

As I mentioned before, the proposed methodology is based on separate analysis and interpolation of GDP components, converted to volume indices versus in the average of year 2015. The additional monthly series used to interpolate those in the national accounts should be correlated with them. The higher the correlation, the more statistically relevant are contents of the interpolated series. On the other hand, if there is poor information in the additional series, there is too much noise (residual) introduced in the series to be interpolated. This requirement is best respected for the following choice:

- For GIND (GVA in Industry) and GCST (GVA in Construction) there are appropriate monthly statistics, and the additional series are Industrial Production index (IND) and Construction Works index (CST), indices published by NIS in constant prices of the year 2015;

- For GTRT (GVA in Trade and Transport), I used a monthly composite index of the turnover volume (TRT) of the following relevant series:

Table 2. Composition of TRT Index (Trade and Transport)

\begin{tabular}{|l|l|}
\hline Monthly series - indices of the turnover & Weights \\
\hline Retail trade & $25,0 \%$ \\
\hline Trade and repair of motor vehicles and motorcycles & $7,1 \%$ \\
\hline Hotels and restaurants & $6,6 \%$ \\
\hline Wholesale trade & $35,6 \%$ \\
\hline Transportation and storage & $25,7 \%$ \\
\hline
\end{tabular}

Source: Author's research TEMPO database, NIS

The weights used for aggregation were calculated based on gross value added of each activity according to Structural Business Survey of the reference year (2015): it should be 
noted that turnover value indices are available for the last two activities, thus it was necessary to deflate these series.

For GOMS (GVA in Other Market Services) I calculated the turnover volume index in services provided to enterprises, excluding transportation and storage services. The weights of these activities are given below:

Table 3. Composition of services rendered mainly to enterprises

\begin{tabular}{|l|l|}
\hline Monthly series - indices of the turnover & Weights \\
\hline Services rendered mainly to enterprises & $100,0 \%$ \\
\hline Transport and Storage & $25,6 \%$ \\
\hline Other Services rendered to enterprises & $74,4 \%$ \\
\hline
\end{tabular}

Source: Author's research, TEMPO database, NIS

The structure also includes information and communication services (24.2\%) and real estate transaction activities (6.3\%) which have grown in recent last years.

Both quarterly aggregates of monthly additional series and national accounts series are not stationary. The results are presented in Table 4.

The value of ADF test ${ }^{13}$ (Schwarz Info Criterion) for the level series is higher than the critical values for the thresholds of significance of $1 \%, 5 \%$ and $10 \%$, so I applied the ADF test for the first difference and the second difference. Exception makes the TRT series that is stationary in level to the 5\% threshold. The value of the ADF test is now lower than the critical values for the series D(GIND), D(IND), D(CST) and D(GOMS), these being thus integrated of 1st order. A test result superior to the critical values is still observed for the series D(GCST), $\mathrm{D}(\mathrm{GTRT})$ and $\mathrm{D}(\mathrm{OMS})$, which are integrated of 2 nd order, due to seasonal factors. Indeed, the ADF test demonstrates that all seasonally adjusted series are integrated of 1st order.

Table 4. Null Hypothesis: Series/D(Series)/D2(Series) has a unit root

\begin{tabular}{|c|c|c|c|c|c|}
\hline & & $\mathrm{D}(\mathrm{GIND})$ & $\mathrm{D}(\mathrm{IND})$ & $\mathrm{D} 2(\mathrm{GCST})$ & $\mathrm{D}(\mathrm{CST})$ \\
\hline \multicolumn{2}{|c|}{ Augmented Dickey-Fuller test statistic } & -18.5503 & -11.4252 & -63.7572 & -26.2400 \\
\hline \multirow[t]{4}{*}{ Test critical values: } & $1 \%$ level & -3.8085 & -3.7696 & -3.8315 & -3.809 \\
\hline & $5 \%$ level & -3.0207 & -3.0049 & -3.0300 & -3.0207 \\
\hline & $10 \%$ level & -2.6504 & -2.6422 & -2.6552 & -2.6504 \\
\hline & & D2(GTRT) & TRT & $\mathrm{D}(\mathrm{GOMS})$ & $\mathrm{D} 2(\mathrm{OMS})$ \\
\hline \multicolumn{2}{|c|}{ Augmented Dickey-Fuller test statistic } & -64.8165 & -3.8648 & -27.3918 & -16.8200 \\
\hline \multirow[t]{3}{*}{ Test critical values: } & $1 \%$ level & -3.8316 & -4.5326 & -4.4983 & -3.8315 \\
\hline & $5 \%$ level & -3.0300 & -3.6736 & -3.6584 & -3.0300 \\
\hline & $10 \%$ level & -2.6552 & -3.2774 & -3.2690 & -2.6552 \\
\hline
\end{tabular}

Source: Author's results using E-views software

\footnotetext{
13 Fuller, W. A. (1976). Introduction to Statistical Time Series. New York: John Wiley and Sons. ISBN 0-47128715-6; Ogunc, A. \& Hill, C. (2008) Using Excel: Companion to Principles of Econometrics, Third Edition. Retrieved January 4, 2017 from: http://econweb.tamu.edu/hwang/CLASS/Ecmt463/Lecture\%20Notes/Excel/Excel_Lessons.pdf
} 
The stationarity can be done if the series are converted into logarithmic "Year-overYear" differences, as it follows:

$$
\Delta \ln (y t)=\ln (y t)-\ln (y(t-4))=\ln [(y t) /(y(t-4)]
$$

In fact, $\Delta \ln (y t)$ has the significance of an annual growth rate of the quarter $(\mathrm{t})$ compared to the corresponding quarter $(\mathrm{t}-4)$ of the previous year. This approach is most often used when estimating the gross quarterly series in the national accounts statistics in the absence of seasonality.

An intuitive picture of the correlation between national accounts and the corresponding additional series in the "annual growth rates" approach is shown in Fig. 1. In addition, I have added the growth rates of GDP components "in preliminary/provisional form". The provisional series was constructed by introducing each year the last 4 quarters of the provisional series published in April of the following year.

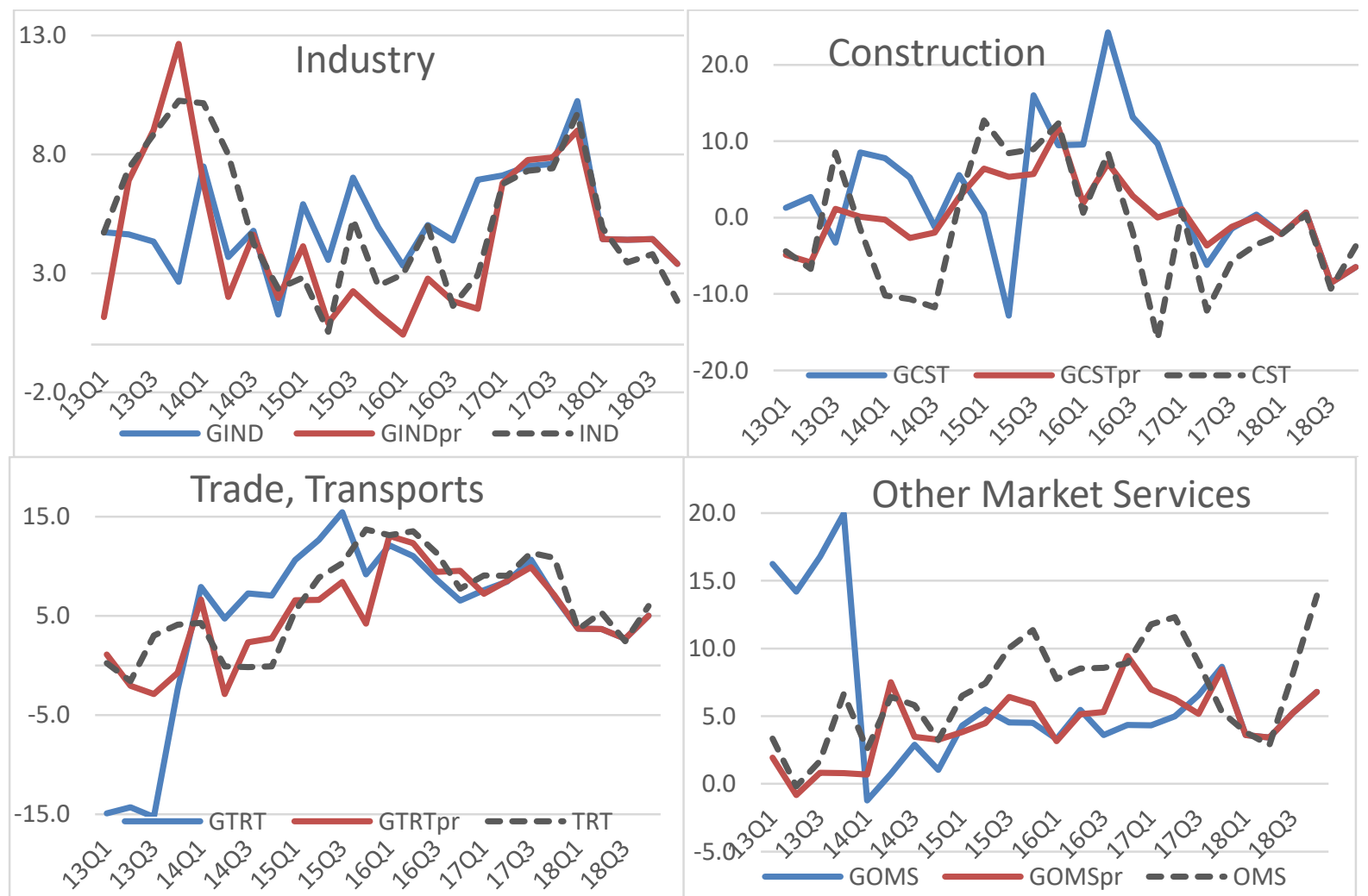

Figure 1. Annual (YoY) growth of national accounts and corresponding additional series Source: Author's results using data from National Institute of Statistics

An acceptable correlation is emerging from 2014 onwards, higher in the case of provisional growth rates. This is due to the many revisions to national accounts data so far, when the GDP series is final for 2013-2016, semi-final for 2017 and provisional for 2018.

The final data are different from the initial estimates, incorporating additional information from the annual surveys. At the same time, the weaker correlation between the quarterly GCST and GOMS series of the national accounts and the corresponding additional series CST (construction works index) and OMS (turnover volume index in services rendered 
to enterprises, excluding transport and storage) is due to the household sector whose activity is included in the national accounts, but not in the additional series.

\section{Estimating Monthly GDP}

For the four components of GDP for which additional data are available, I estimated the quarterly regression equations. In the next step were produced the monthly components of GDP as series predicted by the regression model with monthly explanatory series. These first interpolation series are not consistent with the original ones at the quarterly level.

Thus, in the third step, consistency was achieved by redistributing the quarterly differences between each predicted series and the real one over the months of each quarter.

The structural equation for GIND has the following form:

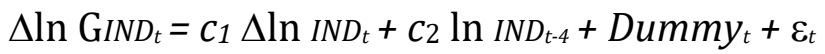

where GIND is the gross value added (GVA) index in industry relative to the base year 2015 and $I N D$ is the quarterly aggregation index of monthly industrial production.

It has been improved by the introduction of dummy variables. The results are presented in Figure 2 with the evolution of the annual growth rates of the interpolated GVA in industry and the additional monthly industrial production.

\begin{tabular}{|c|c|c|c|}
\hline \multicolumn{4}{|c|}{ Dependent variable is $\Delta \ln G I N D_{t}$} \\
\hline variable & coeff. & s.e. & $t$-val \\
\hline$\Delta \ln I N D_{t}$ & 0,651 & 0,103 & 6,330 \\
\hline$\overline{l n} I N D_{t-4}$ & 0,005 & 0,001 & 4,403 \\
\hline $\mathrm{D} 2014 \mathrm{q} 2_{t}$ & $-0,037$ & 0,012 & $-3,080$ \\
\hline $\mathrm{D} 2016 \mathrm{q} 4_{t}$ & 0,025 & 0,012 & 2,159 \\
\hline \multicolumn{2}{|c|}{ Durbin-Watson } & \multicolumn{2}{|l|}{2,029} \\
\hline \multicolumn{2}{|l|}{$\mathrm{R}^{2}$} & \multicolumn{2}{|l|}{0,73} \\
\hline \multicolumn{2}{|l|}{ s.e. } & \multicolumn{2}{|l|}{0,011} \\
\hline
\end{tabular}

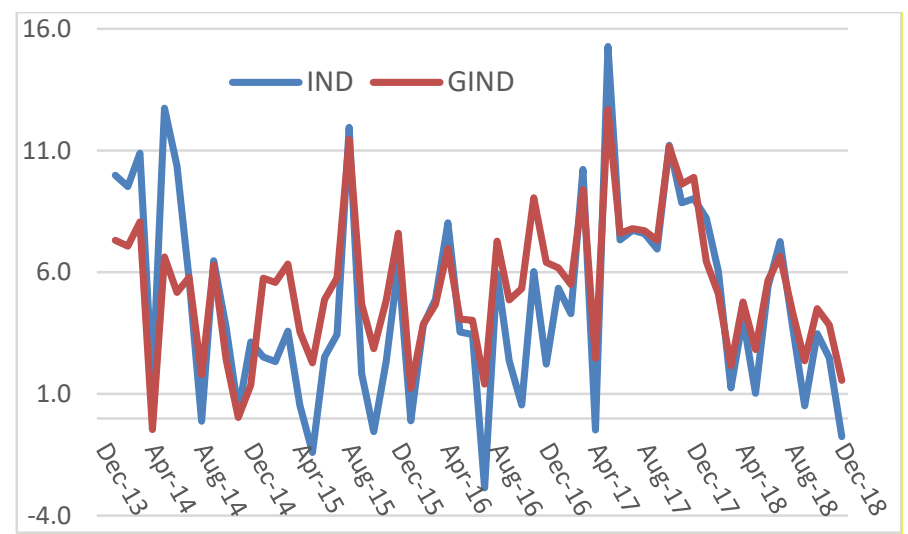

Figure 2. Regression output and annual growth rates of monthly GVA in industry Source: Author's results using E-views7

Generally, the correlation between the two series is consistent since the industry activity in national accounts is mainly driven by the non-financial companies sector and the industrial production index is built on data reported by this sector. Households produce an industrial production in the processing of agricultural products in their own homes, the percentage being reduced compared to firms.

The model used for GVA interpolation in construction is the following:

$\Delta \ln \mathrm{GCST}_{t}=c_{1} \Delta \ln \mathrm{CST}_{t}+c_{2} \ln \mathrm{GCST}_{t-4}+c_{3} \ln \mathrm{CST}_{t-4}+$ Dummy $_{t}+\varepsilon t$

where GCST is the gross value added (GVA) index in construction.

The specification of the model above is based on the partial correlation between the annual dynamics of construction activity in the national accounts and the quarterly aggregation index of monthly construction works (Figure 3). 


Dependent variable is $\Delta \ln$ GCST $_{t}$
\begin{tabular}{|l|l|l|l|}
\hline variable & coeff. & s.e. & $t$-val \\
\hline$\Delta \ln$ CST $_{t}$ & 0,617 & 0,167 & 3,695 \\
\hline $\ln$ CSST $_{t-4}$ & $-0,208$ & 0,064 & $-3,243$ \\
\hline $\ln$ CST $t-4_{4}$ & 0,220 & 0,065 & 3,387 \\
\hline D2015q2t & $-0,262$ & 0,060 & $-4,383$ \\
\hline D2016q $_{t}$ & 0,169 & 0,063 & 2,684 \\
\hline
\end{tabular}

\begin{tabular}{|l|l|}
\hline Durbin-Watson & 1,37 \\
\hline $\mathrm{R}^{2}$ & 0,68 \\
\hline s.e. & 0,054 \\
\hline
\end{tabular}

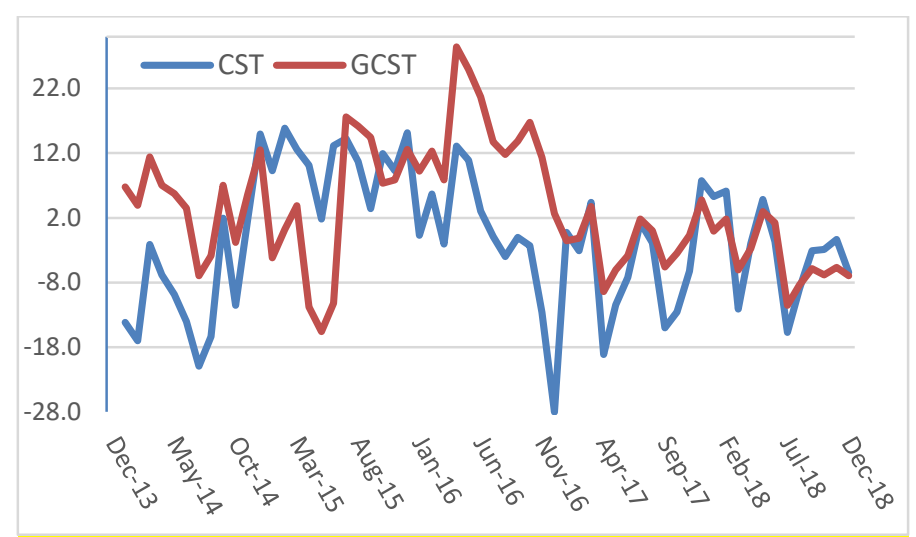

Figure 3. Regression output and annual growth rates of monthly GVA in construction Source: Author's results using E-views7

In the construction field, we have a weaker correlation for observations at the beginning of the analysis period. In the national accounts, the gross value added from construction is finally estimated for the period 2013-2016 and the quarterly series have been significantly revised by adding the contribution of sectors such as households and public administration. At the same time, construction activity includes an unobservable component (hidden economy). Thus, GCST series of national accounts encompasses much more information than the CST series that describes the activity specific to the firm sector.

The structural equation for GTRT has the following form:

$\Delta \ln \mathrm{GTRT}_{t}=c_{1} \Delta \ln T R T_{t}+c_{2} \ln T R T_{t-4}+$ Dummy $_{t}+\varepsilon_{t}$

where GTRT is the gross value added (GVA) index in Trade and Transport. The explanatory variable is $T R T$, the quarterly aggregation turnover index of wholesale and retail trade, transport and storage, hotels and restaurants activities.

\begin{tabular}{|c|c|c|c|}
\hline \multicolumn{4}{|c|}{ Dependent variable is $\Delta \ln \mathrm{GTRT}_{t}$} \\
\hline variable & coeff. & s.e. & $t$-val \\
\hline$\Delta \ln \mathrm{TRT}_{t}$ & 0,309 & 0,106 & 2,905 \\
\hline $\ln \mathrm{TRT}_{t-4}$ & 0,012 & 0,002 & 6,120 \\
\hline $\mathrm{D} 2015 \mathrm{q} 2 t$ & 0,040 & 0,019 & 2,088 \\
\hline $\mathrm{D} 2015 \mathrm{q} 3_{t}$ & 0,059 & 0,019 & 3,044 \\
\hline $\mathrm{D} 2018 \mathrm{q} 2_{t}$ & $-0,036$ & 0,019 & $-1,868$ \\
\hline $\mathrm{D} 2018 \mathrm{q} 3_{t}$ & $-0,039$ & 0,020 & $-1,930$ \\
\hline \multicolumn{2}{|c|}{ Durbin-Watson } & \multicolumn{2}{|l|}{1,35} \\
\hline \multicolumn{2}{|l|}{$\mathrm{R}^{2}$} & \multicolumn{2}{|l|}{0,72} \\
\hline \multicolumn{2}{|l|}{ s.e. } & \multicolumn{2}{|l|}{0,019} \\
\hline
\end{tabular}

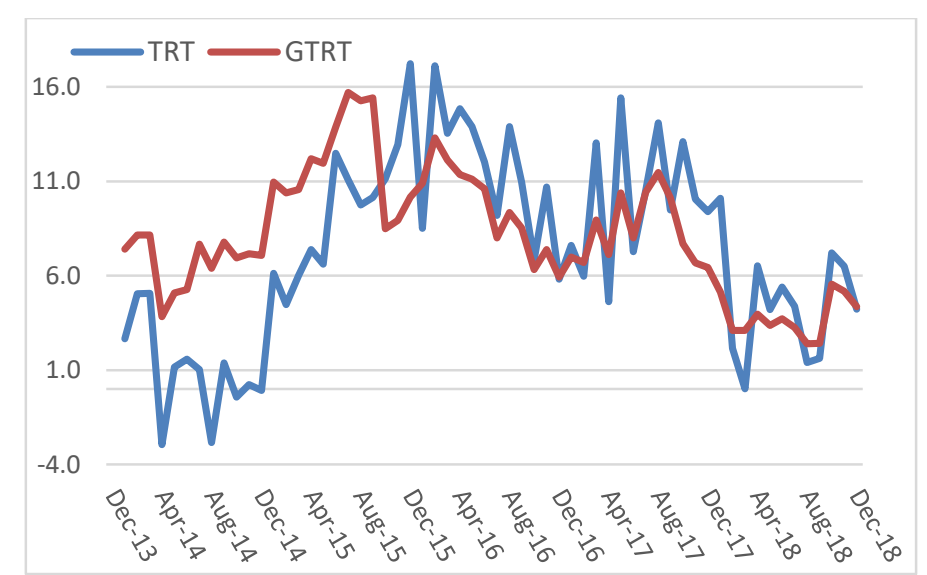

Figure 4. Regression output and annual growth rates of monthly GVA in Trade and Transport Source: own calculation using E-views7

The turnover in trade is a different indicator than gross value added (GVA) in statistical terms of coverage and content. The turnover is a component of production and GVA is the difference between production and intermediate consumption. Thus, the correlation between these indicators is weaker for the first half of the period of analysis when the national accounts are in the final version, but a general correlation of trends is observed. The 
objective of the analysis being an interpolation one, the results are satisfactory, so that the monthly evolution of the series in the national accounts contains relevant information related to fluctuations in trade and transport activity.

Other Market Services in the national accounts (GOMS) refer to information and communications, real estate transactions, secretarial activities and other support services rendered mainly to enterprises, which are also contained in the monthly turnover series (OMS) presented in Section 2. Thus, the econometric equation has the following form:

$\Delta \ln \mathrm{GOMS}_{t}=c_{1} \Delta \ln O M S_{t}+c_{2} \ln O M S_{t-4}+$ Dummy $_{t}+\varepsilon_{t}$

Dependent variable is $\Delta \ln \mathrm{GOMS}_{t}$
\begin{tabular}{|l|l|l|l|}
\hline Variable & coeff. & s.e. & $t$-val \\
\hline$\Delta \ln 0 \mathrm{MS}_{t}$ & 0,296 & 0,086 & 3,430 \\
\hline $\ln \mathrm{OMS}_{t-4}$ & 0,005 & 0,002 & 2,713 \\
\hline $\mathrm{D}^{2014 q} 1_{t}$ & $-0,038$ & 0,011 & $-3,461$ \\
\hline $\mathrm{D} 2014 \mathrm{q} 2_{t}$ & $-0,030$ & 0,010 & $-2,893$ \\
\hline $\mathrm{D} 2017 \mathrm{q} 4_{t}$ & 0,047 & 0,011 & 4,458 \\
\hline
\end{tabular}

\begin{tabular}{|l|l|}
\hline Durbin-Watson & 1,83 \\
\hline $\mathrm{R}^{2}$ & 0,83 \\
\hline s.e. & 0,010 \\
\hline
\end{tabular}

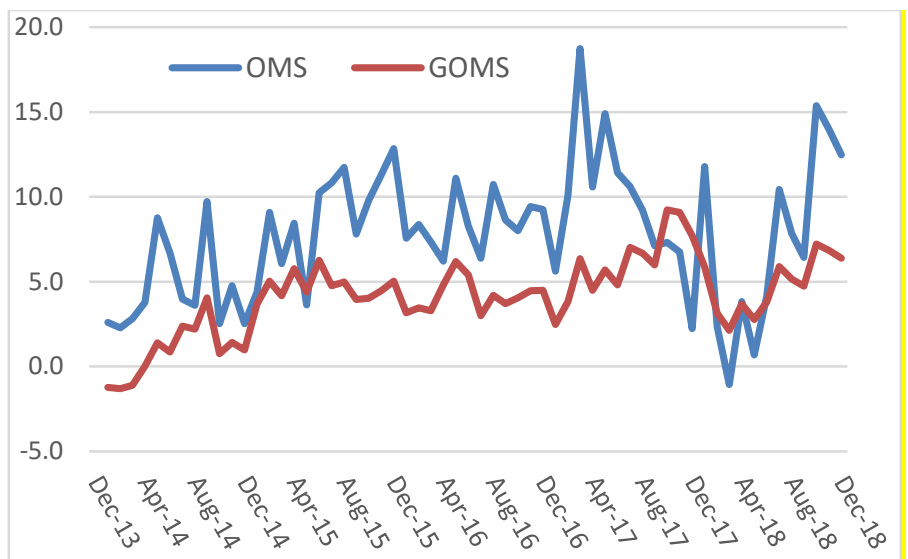

Figure 5. Regression output and annual growth rates of monthly GVA in Other Market Services

Source: own calculation using E-views7

The correlation between the indicators is good according to the regression results. There is a higher volatility of the monthly turnover series, which is normal because it reflects monthly earnings and the gross value added includes salary costs and profits.

The last step is to calculate the monthly series of "Private Gross Value Added (GPRIV)" by summing up the four components and building the corresponding quarterly series. The difference between GDP and GPRIV is a series correlated to the public sector (GPAD) and the agriculture (GAGR) activities.

$$
\begin{aligned}
& G P R I V=G I N D+G C S T+G T R T+G O M S \\
& G O T H=G D P-G P R I V \\
& \text { or } \quad G O T H=N T P+G P A D+G A G R
\end{aligned}
$$

There are no monthly data available in constant prices for other activities (GOTH). A simple autoregressive model is therefore suitable for the interpolation of this series:

$\Delta \ln \mathrm{GOTH}_{t}=c_{0}+c_{1} \Delta \ln \mathrm{GOTH}_{t-1}+$ Dummyt $_{t}+\varepsilon_{t}$

and $\quad \Delta \ln \mathrm{GOTH}_{t}=\ln \mathrm{GOTH}_{t}-\ln \mathrm{GOTH}_{t-4}$

The econometric estimates lead to a zero value for the $c_{0}$ coefficient, so I choose for the following simplified form:

$\Delta \ln \mathrm{GOTH}_{t}=c_{1} \Delta \ln \mathrm{GOTH}_{t-1}+$ Dummyt $_{t}+\varepsilon_{t}$ 


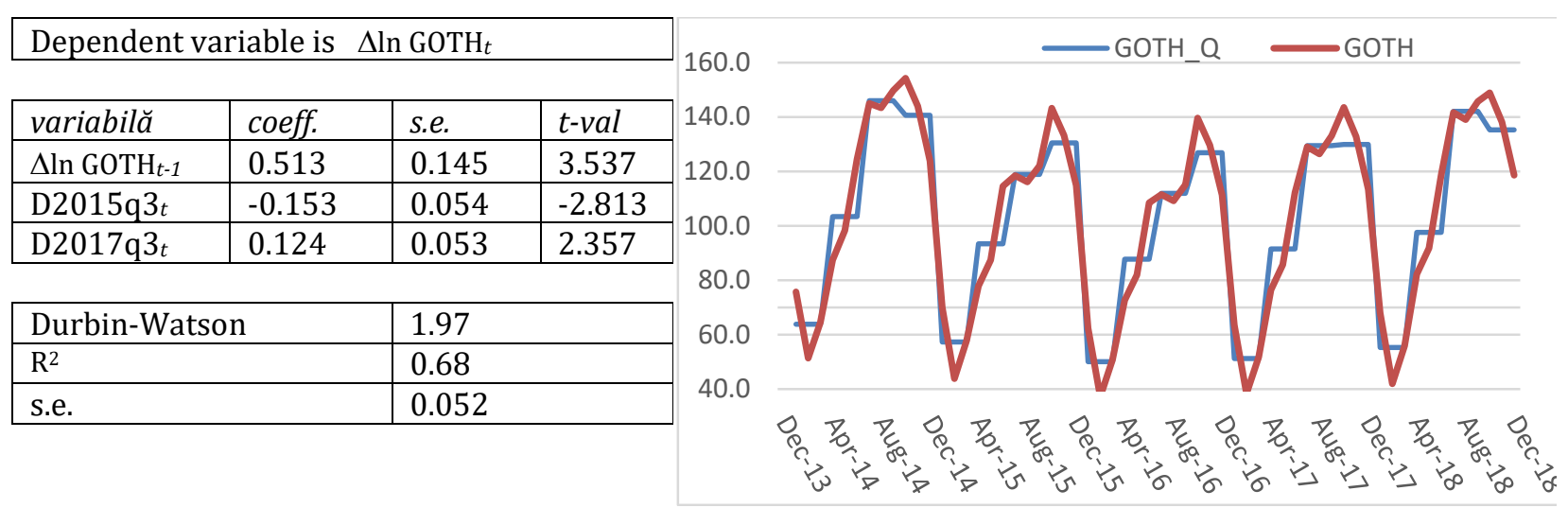

Figure 6. Regression output and monthly interpolation of Other GDP activities including public administration and agriculture (volume indices versus the average of 2015) Source: own calculation using E-views7

The trend of the quarterly series is also monthly included: the months of the accelerated growth quarters also have a high dynamics and the first quarter, which strongly reduces its activity compared to the fourth quarter, will take this fall in February. In addition, there is a peak of activity in October because of seasonality of the agriculture and there is a minimum in February when value added tax revenues are lower.

The monthly indicator of GDP is the sum of the two series GPRIV and GOTH.

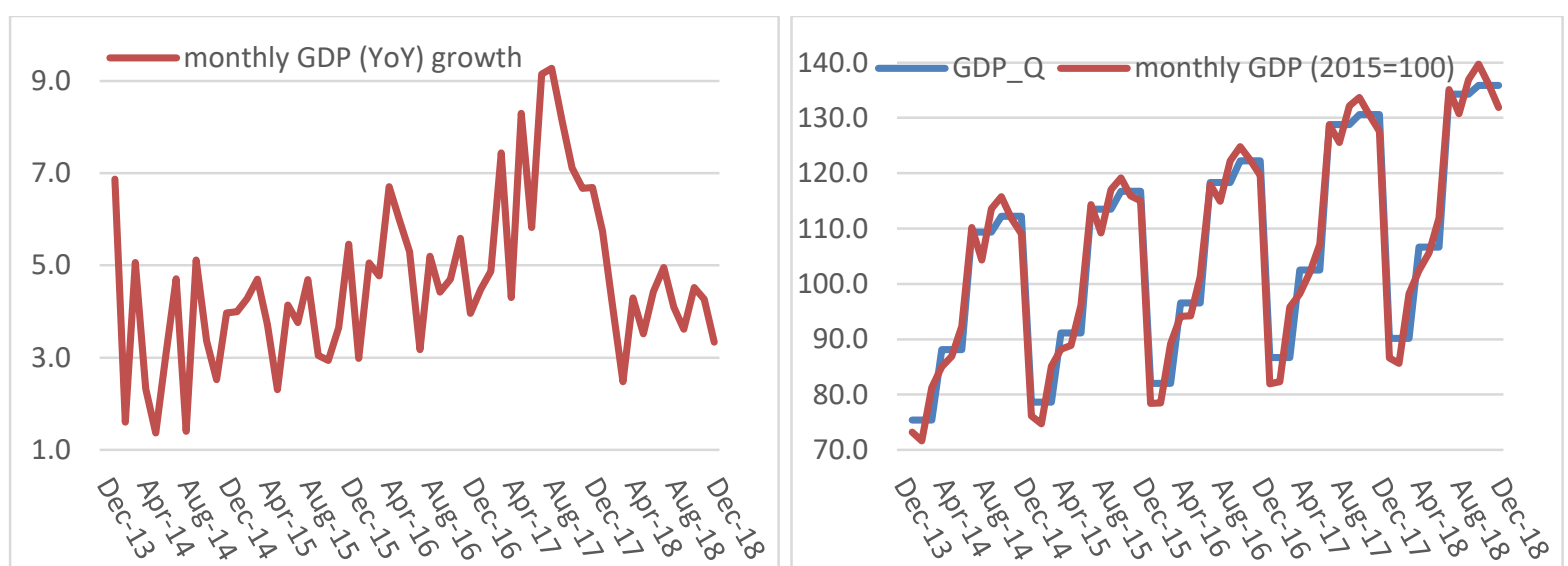

Figure 7. Annual (YoY) growth of monthly GDP and evolution of series in level (volume indexes versus the average of 2015)

Source: own calculation using E-views7

Figure 7 shows the evolution of the monthly real GDP and of the corresponding annual growth series over the period 2014-2018. A strong seasonal trend is visible in the GDP series in levels, similar to the quarterly pattern. Seasonality is eliminated in "annual growth rates" representation where the highest dynamics was recorded in August $2017(+9.3 \%)$ and the lowest increase in August 2014 (+1.4\%). Starting in January 2018, economic growth slow down, following the adjustment of private consumption and industry, amid a pronounced base effect and weakening external demand in the euro area.

An estimate of monthly GDP at current prices may be more accurate because an interpolation of the GOTH series can be considered in this case using monthly data of indirect 
taxes and gross public sector wages.

\section{Conclusion}

Generally, a monthly GDP indicator is estimated by econometric methods to include the maximum of information from the various sectors of economic activities. The more monthly series are used in the estimation procedure, the monthly GDP is closer to its statistical significance, namely quantifier of global economic activity. Common models turn to one or two monthly series, for example, the industrial output index and the retail turnover index.

In this article, I proposed a method that uses all the relevant series available at the monthly level. Another element of originality is the interpolation of the "gross series" instead of the seasonally adjusted series. In order to avoid seasonality problems, I converted the initial monthly data into growth indices compared to the same period (month/quarter) of the previous year, equivalent to the logarithm difference between each two similar periods separated by one year.

In addition, various statistical aspects have been highlighted, such as quarterly GDP revisions due to the emergence of new information from annual surveys, even with the change of the statistical calculation methods, different at the time of GDP estimation in initial or final version. These statistical operations have produced changes to the quarterly series in several stages. Thus, there is a weaker correlation between the more remote values of the series and the values of additional variables that are calculated from the monthly surveys. The correlation is stronger for the observations from the past two years, as they are estimated in the preliminary version. Thus, I noticed an inconsistency in data correlation for 2011-2012, which is why I considered 2013 as the start of the series.

The monthly GDP estimate does not require strict adherence to the conditions imposed by the econometric theory. Thus, statisticians Chow and Lin, who have approached worked with series in levels that were not stationary. What we are interested in is finding a form of econometric equation with statistical significance that best expresses the correlation between a GDP component and the corresponding additional series, in order to extract its specific pattern at the monthly level and introduce it into the series that is interpolated.

Finally, based on the previous results, we can reach an important conclusion. First, all the econometric methods that use additional monthly information provide a reliable pattern of monthly GDP by incorporating the effects of relevant economic activities (industry, services, construction).

Secondly, our approach used the same statistical procedure when estimating the monthly series as for estimating the quarterly series from the national accounts. Thus, the components of GDP are interpolated on the basis of information from the monthly statistical series that are simultaneously used by the national accounts in the provisional quarterly estimates. At the same time, we considered as a general rule the maintenance of the same type of correlation both at quarterly and monthly level between the dynamics of the series in the national accounts and the explanatory series used for interpolation.

For future study, I was proposing to build a model for GDP components by the demand method. Here are data relevant for estimating: consumption, investment, imports and exports. At the same time, it is useful to interpolate the nominal GDP series that will include additional available information on public sector activity (salaries, indirect taxes).

The presented method may extend to the seasonally adjusted series, but the structure of the econometric equations will be different in this approach (series expressed in 
logarithmic differences ( $\mathrm{t} / \mathrm{t}-1$ ) or growth rates from month to month).

It is important to mention that, as with all short-term statistics, the utility of the monthly GDP is important for several reasons: it allows estimating the GDP as close to reality as possible quarterly at least one month before the data is published; provides a monthly series that fully describes the evolution of the short-term economy and, consequently, it can be correlated with other relevant financial and macroeconomic indicators such as inflation, stock trading value, disposable incomes, budget revenues, those being useful to guide macroeconomic policy and risk assessment, in the short term.

\title{
References
}

Astolfi R., Ladiray D., Mazzi G., Sartori F., Soares R., (2001), A Monthly Indicator of GDP for the Euro-zone, Office for Official Publications of the European Communities, European Commission.

Bernanke B., Gertler M., Watson M., (1997), Systemic monetary policy and the effects of oil price shocks, Brookings Papers on Economic Activity, (1):91-157.

Chow G., Lin A.L., (1971), Best linear unbiased Interpolation, Distribution and Extrapolation of Time Series by Related Series, The Review of Economics and Statistics 53(4), 372375.

Cuche N., Hess M., $(1999,2000)$, Estimating monthly GDP in a general Kalman filter framework: evidence from Switzerland, Economic \& Financial Modelling, University of California at Berkeley.

Gregoir S., (1994), Note on temporal disaggregation with simple dynamic Models, Workshop on Quarterly National Accounts, Paris 5-6 December 1994.

Harvey A., (1989), Forecasting Structural Series Models and the Kalman Filter, Cambridge University Press.

Harvey A., Pierse R., (1984), Estimating missing observations in economic time series, Journal of the American Statistical Association, 79(385):125-131.

Pinheiro M., Coimbra C., (1993), Distribution and Extrapolation of Time Series by Related Series Using Logarithms and Smoothing Penalities, Economia v.XVII, pg.359-374.

Salazar E., Smith R., Weale M., Wright S., (1994), Indicators of monthly National Accounts, Workshop on Quarterly National Accounts, Paris 5-6 December 1994.

Eurostat, Handbook on quarterly national accounts, ISSN 1681-4789 2013 edition ISSN 2315-0815 https://ec.europa.eu/eurostat/cache/metadata/en/namq 10 esms.htm; Flash estimation of the quarterly Gross Domestic Product for the euro-zone and the European Union Eurostat methodology.

\author{
Abreviations \\ GDP Gross Domestic Product \\ NIS National Institute of Statistics \\ GVA Gross Value Added \\ GCST Gross Value Added in Construction \\ GTRT Gross Value Added in Trade and Transport \\ GOMS Gross Value Added Other Market Services \\ GOTH Gross Value Added Other Activities and Taxes on Products \\ GPAD Gross Value Added in Public Administration \\ GAGR Gross Value Added in Agriculture \\ NTP Net Taxes on Product \\ CST Construction \\ OMS Other Market Services \\ TRT Trade and Transport \\ GPRIV Private Gross Value Added
}

